\title{
Study on Autonomous Learning of College Students in Specialized English
}

\author{
Wei Zhang \\ College of Humanities \\ Tianjin Agricultural University \\ Tianjin, China
}

\begin{abstract}
Presently, the capability of learning autonomously has become a more and more important index in measuring quality of university students. But the truth is that many college students are lack of motivation or ability to learn autonomously, especially in the field of specialized English. The following discussion will focus on how to help student to become an autonomous learner in learning specialized English. The context of article includes: basic concepts introduction, status analysis, cause analysis, countermeasures, and conclusion. In the article interview method and literature research method will be used to find out why students are lack of capability in autonomous learning, and how to motive them and help them to be autonomous learners. And we wish that this article will be helpful for those who are facing the similar problems.
\end{abstract}

Keywords-Autonomous Learning; Specialized English; College Students; Non-English Majors

\section{BASIC CONCEPTS}

\section{A. Autonomous Learning}

Autonomous learning is a concept that different from traditional reception learning. It refers to the capability of students to take charge of one's own learning [1].

Generally speaking, autonomy is a situation in which the learner is totally responsible for all decisions concerned with his (or her) learning and the implementations of those decisions.

\section{B. Specialized English}

Specialized English is a term used by universities in China. It refers to the English for Specific Purpose (ESP) offered to non-English majors. ESP is a subset of English as a second or foreign language. It usually refers to teaching the English language to college students or people already in employment with reference to the particular vocabulary and skills they need. As with any language taught for specific purpose, a given course of ESP will focus on one occupation or profession, such as Technical English or English for Human Resource Management.

\section{PRESENT STATUS ON AUTONOMOUS LEARNING OF COLLEGE STUDENTS}

A. Students are Lack of Interest and Confidence to Learn Autonomously

Currently, most of learners of specialized English in universities are non-English majors. From the survey conducted, we find that non-English majors consider English courses as non-main courses. They are lack of proper understanding on the meanings of studying specialized English. A fairly large number of college students show indifferent attitude to English learning. They only learn to pass final examinations or to get English certificates, such as: CET4 or TEM4, etc. Additionally, to learn specialized English, students are required to possess a large volume of vocabulary and the capability to understand long and difficult sentences. Those all scared students off the course and make them lost their confidence on English learning.

\section{B. Students are Lack of Capability and Motivation in Autonomous Learning}

In traditional English education method, teachers are dominators, and they emphasize more on vocabulary and grammar. Students grown up within the environment become incapable and unmotivated in learning autonomously [2]. Their learning method only limited to rote memorization. They learn for examination. From the survey we found most of college students of non-English majors presently show indifference on make additional efforts on learning specialized English. They take specialized English as 'unimportant' and are unwilling to make additional efforts other than rote memorization. They consider that learning specialized English will not be helpful for improving their competency in their specialized field. So they are unmotivated.

\section{Students are Lack of Self-management Ability}

Presently, college students are thought to be seriously lack of self-management abilities. The lack of the ability mainly reflected on: students are lack of ability on planning their own learning activities; students are lack of ability on monitoring their own learning outcome; and students are lack of ability on assessing themselves [3]. Especially in learning specialized English. Many students can't understand the goal and 
objectives of specialized English, let alone to plan, monitor and assess their own learning activities.

\section{CAUSE ANALYSIS}

\section{A. The Setting of Specialized English are Problematic}

Specialized English is different from college English, but also different from other specialized courses taught in Chinese. The objectives of the course should focus on raising students' ability to take English as a tool to assist them in scientific research. Presently the setting of specialized English is not sufficient to achieve the objectives.

Generally speaking, class hours allocated for specialized English in universities in China always ranges from $36 \mathrm{~h}$ to $72 \mathrm{~h}$. The content of the courses always focus on readings, and translations. These are all content of college English, so it is difficult for students to tell the different between college English and specialized English. The problematic setting of specialized English made it difficult for student to get a proper understanding on the course. In addition, the courses are always offered to non-English majors. For them English courses are not main courses. They tend to make less effort on learning.

Further more, the materials used in specialized English are always those English thesis or readings with strong speciality. Thus these materials always include terms and long and difficult sentences. This makes it more difficult for students to learn and further discourage them from learning autonomously.

\section{B. Teaching Mode of Specialized English is Limited}

Teaching mode is the teaching structure and teaching process established under the direction of teaching thoughts and method [4]. Different teaching modes have different influence on students' ability of autonomous learning. Generally speaking, class lecture is thought to have negative influence on the development of capability to learn autonomously. Under this mode, teachers are providers of the knowledge and students are receivers. The method ignores students major status in learning, discourages students' individuality and hinders the development of creativity, consciousness and enthusiasm in learning [5].

The teaching mode of specialized English is limited to class lecture. Teachers are only emphasize on unilaterally instilling knowledge on students. Students on the other side, are only forced to learn, and are lack of sense of participation.

\section{Traditional Idea of Family Education Affects Students \\ Ability on Self-management and Autonomous Learning}

For a long time, traditional idea greatly constraints the family education of families in China. In daily family education parents are always tend to take on all things for children and pay less attention to raise their self-management abilities. Inside of helping their children to develop their own individualities, to be independent, and to manage themselves, parents tend to make decision for their children, satisfy with all their needs, and deal with all problems they meet. That's the deeper reason that delays the development of students' selfmanagement ability and autonomous learning

\section{COUNTERMEASURES}

\section{A. Refine the Setting of Specialized English and Encourage} Bilingual Specialized Courses to be Offered

Setting of the specialized English should be refined and more bilingual specialized courses should be offered as supplement. As mentioned in 3.1 above, there is a dilemma in the setting of the course. Specialized English should serve as an English course and a specialized course two in one. Actually, it is difficult to integrate the two function into one course. Hence, the course should be divided to two parts. For one part, 36h$54 \mathrm{~h}$ should be allocated for teaching students common specialized terms and expressions in English version. For another part, bilingual specialized courses should be offered for students to further practice specialized English and to develop their capability in using English as a tool to deal with practical problems. Using Human Resource Management as a example. For students of HRM, 36h-54h's English for HRM should be offered to teach them specialized terms and expressions, such as: human resource management, performance management, compensation and benefits, training and development, etc. Then, other specialized courses, such as recruitment selection and hiring, career management, performance management, etc., should be offered in bilingual form. These bilingual specialized courses could serve to teach students specialized knowledge in HRM and to help students practice specialized English better at the same time. Moreover, to offer bilingual courses will also be beneficial for teachers of the course. They can have the opportunity to improve their English ability and further to develop their ability to conduct scientific research in English.

\section{B. Introduce Diversified Teaching Mode to Motivate and Prompt Students to Learn Autonomously}

Diversified teaching mode should be introduced to motive students to actively take part in teaching process of specialized English. Diversified teaching mode can be a supplement for traditional class lecture, and provide more opportunity for students to interact with teachers.

\section{- $\quad$ Group cooperative learning}

In this mode teachers act more like an organizer and coordinator. The whole process should follow the following pattern:

Step 1: a set of topics been provided for students;

Step 2: grouping, students should work in groups of 4-6;

Step 3: list specific tasks of each students;

Step 4: complete all tasks by group-working;

Step 5: make a written report for class discussion;

Step 6: teacher feedback;

Step7: refine and submit the report.

By using group cooperative learning, every students can be actively involved in the whole learning process. Besides, step3, 
step 6 and step 7 further guarantee the effectiveness and efficiency of the mode.

\section{- $\quad$ Stratification teaching}

This mode focus on setting different goals for different students, and it aims to help students of different English level to improve their English ability. The mode is particularly suitable for specialized English. Because students' interest and level of English are very different, some of them are interested in English and they have already got CET 4 or even CET 6 certificates; some of them, on the contrary, are not interested in English and some of them even far from passing CET 4 exam. Give the same class assignment for different students, under this circumstance, is not the right choice, and will make students who are not good at English become more uninterested. Stratification teaching provides a solution for students of different English level. In specialized English, for students who are good at English, more specialized assignment should be offered to them to help them improve their ability of using English as a tool to solve practical problem; for students who are not good at English and uninterested, class assignment should be less specialized and more interested to reduce the difficulties in English and raise students confidence and interest in learning English.

\section{- Web-based instruction}

This teaching mode provides a channel to extend the lessons beyond traditional classroom teaching to include multimedia and internet technology. Multimedia and internet facilitate teachers and students to interact anytime anywhere they want. They can discuss specialized issues via BBS, E-mail, WeChat or other specialized internet platform. Web-based instruction releases students and teachers from classroom and limited means of teaching. It is very effective to prompt enthusiasm and initiative of students.

\section{Develop Students' Capability of Autonomous Learning}

- $\quad$ Train students and show them how to learn autonomously

Specific courses should be provided to show students how to learn autonomously. The courses should include:

1) courses to show students how to learn autonomously via multimedia and internet technology;

2) courses to show students how to learn specific specialized courses, specialized English for instance.

- $\quad$ Establish assessment system to evaluate autonomous learning capability
Make assessment of each course contribute to scientific management of learning activity for students. For specialized English, course assessment should make up of following parts:

1) Self-assessment: students should make an assessment for themselves;

2) Peer-assessment: students of same study group should make assessment for every other members of the group;

3) Teacher-assessment: teacher of the course should make assessment for each student.

This assessment system can effectively supervise, improve and promote autonomously learning activity of students.

\section{CONCLUSION}

In conclusion, the whole discussion here shows that how to motivate students and to develop their capability to learn autonomously is a crucial problem, especially in the field of specialized English. Due to inappropriate course setting, rigid teaching mode, and paternalistic family education, in universities, students appear to be lack of interest, unmotivated, and lack of self-management ability, especially in learning specialized English. To solve the problems, we should make efforts to refine the setting of the course, introduce diversified teaching mode, and help students to develop their learning ability by offering them proper training and supervision.

\section{REFERENCES}

[1] He Jisheng. Meanings, Constitution and Cultivation of Autonomous Learning Capability for College Students[J]. Journal of Hunan University of Science and Engineering. 2012(5):75-78. (In Chinese)

[2] Hu Xinmei. Discussion on Cultivation of Autonomous Learning Capability for College Students. Education and Vocation. 2015(27):110112. (In Chinese)

[3] An Wuhuai. Cultivation of Autonomous Learning Abilities for College Students[D]. Chongqing: Southwest University. 2014. (In Chinese)

[4] Liu Yuanyuan. Research on Class Teaching Mode Reform Based on Autonomous Learning of Non-English Majors[J]. Overseas English. 2017(9):63-64. (In Chinese)

[5] Sui Xin, Wang Chao. Discussion on Cultivation of Autonomous Learning Capability of Non-English Majors in Network Environment[J]. Finance Theory and Teaching. 2018(2):113-115. (In Chinese)

[6] Shen Lijuan. Strategic Teaching Based on Research on Autonomous Learning Activity of Non-English Majors[J]. Journal of Xinyang Agriculture and Forestry University. 2017(2):147-148+151. (In Chinese) 